\title{
Commentary Disinfection of the hospital water supply: a hidden risk to dialysis patients
}

\author{
Nicholas A Hoenich
}

Institute for Cell and Molecular Biosciences, Faculty of Medical Sciences, Newcastle University, Newcastle upon Tyne, NE2 4HH, UK

Corresponding author: Nicholas A Hoenich, nicholas.hoenich@ncl.ac.uk

Published: 1 December 2009

This article is online at http://ccforum.com/content/13/6/1007

(c) 2009 BioMed Central Ltd

See related research by Bek et al., http://ccforum.com/content/13/5/R162
Critical Care 2009, 13:1007 (doi:10.1186/cc8158)

\begin{abstract}
Water suitable for drinking is unsuited for use in the preparation of haemodialysis fluid and undergoes additional treatment. The primary component of the additional treatment is reverse osmosis, which does not remove low-molecular-weight contaminants, and the water treatment system must contain carbon beds or filters to ensure effective removal of such contaminants. The recent article by Bek and colleagues highlights an unrecognised issue with respect to chemicals that may be added to the water within hospitals to ensure that the distribution network is free of pathogens (for example, Legionella, pseudomonas, and mycobacteria) and underlines the need for personnel responsible for dialysis in a renal or intensive care setting to be aware of any potential effects that disinfection of the hospital water treatment system may have on the product water used in the preparation of dialysis fluid. Such awareness requires communication and the sharing of information between clinical and facilities staff.
\end{abstract}

The article by Bek and colleagues [1] in the previous issue of Critical Care raises an important and frequently unrecognised issue concerned with haemodialysis in a hospital setting. Renal services in hospitals frequently derive their water supply from the hospital water distribution network. Such networks are complex, can contain regions of low flow or stagnation, and frequently incorporate a storage tank to ensure adequate water pressure and availability of supply in times of peak demand. In common with any water distribution network, those in the hospital are subject to biofilm formation. A number of pathogens (for example, Legionella, pseudomonas, and mycobacteria) thrive in the biofilm and may be up to 3,000 times more resistant to bacteriostats added to the public water supply than their free-floating counterparts $[2,3]$.

To minimise risk from nosocomial infections, hospitals employ a range of preventive strategies to control the formation of biofilm, including the use of chemical agents such as silverstabilised hydrogen peroxide [4,5]. Hydrogen peroxide is an oxidising agent, which at concentrations used for disinfection is considered safe to drink, enabling it to be used in 'live' buildings, and is eco-friendly since it breaks down to water and oxygen. Its effectiveness and stability can be enhanced by the addition of trace amounts of silver (silver-stabilised hydrogen peroxide).

For dialysis applications, the unsuitability of drinking water has long been recognised and water for use in dialysis units undergoes additional treatment to reduce contaminant levels to below that specified in national or international standards dealing with water for use in dialysis [6]. Although the design of the water treatment plants used in dialysis units is dependent upon the quality of the feed or raw water and the uses that the treated water is put to within the dialysis unit (conventional haemodialysis, reprocessing of dialysers, or the production of infusate for 'on-line' therapies), the major components of treatment systems are pretreatment filtration, carbon filters that may be granular or in the form of a carbon block, and reverse osmosis units. The primary element for chemical contaminant removal is the reverse osmosis unit, which works by using pressure to force a solution through a membrane, retaining the solute on one side and allowing the pure solvent to pass to the other side. This is the reverse of the normal osmosis process, the natural movement of solvent from an area of low solute concentration, through a membrane, to an area of high solute concentration when no external pressure is applied.

Low-molecular-weight chemical contaminants such as chlorine or hydrogen peroxide pass through the reverse osmosis membrane and are removed only by carbon filtration; however, at high concentrations, there may be incomplete removal. If carbon filtration is absent, then any low-molecularweight compounds have the potential to cross the semipermeable membrane in the dialyser and interact with the patient's blood. 
The article by Bek and colleagues [1] describes such an occurrence and demonstrates a relationship between methemoglobin concentrations in patients and the presence of hydrogen peroxide. The incident that they describe is by no means unique. Recently, the addition of silver-stabilised hydrogen peroxide to the water distribution system of a hospital in the UK resulted in a fatality and caused harm to a number of patients undergoing dialysis treatment [7]. Davidovits and colleagues [8], in 2003, also described the clinical sequalae associated with the use of this compound in children.

Although in these cases the causative agent of clinical complications is silver-stabilised hydrogen peroxide, it is quite conceivable that alternative antibacterial additives may also affect patient well-being. For instance, water utilities are increasingly using chlorine dioxide as an alternative to chlorine and chloramine. Chlorine dioxide breaks down in water to yield chlorite, chlorate, and chloride ions. Currently, there is little information about the potential for chlorine dioxide and its daughter products to be toxic to haemodialysis patients, although review of the literature yields a report of 17 dialysis patients treated with water containing 0.02 to $0.08 \mathrm{mg} / \mathrm{L}$ of chlorite ions and no detectable chlorate ions. No adverse effects were described, but potentially important haematological parameters were not measured [9].

Important lessons can be learned from these incidents. First, whilst reverse osmosis is a highly efficient approach to remove chemical contaminants, low-molecular-weight compounds are not removed. Such compounds may be removed by adsorption to carbon, and the water treatment system must therefore contain carbon beds or filters. Personnel responsible for dialysis in a renal or intensive care setting need to be aware of any potential effects that disinfection of the water treatment system or the feed water may have on the product water used in the preparation of dialysis fluid. Such awareness requires communication and the sharing of information between clinical and facilities staff, who should be aware of the risks and hazards that may be posed to special patient groups if chemicals are introduced into the water supply. Guidance pertaining to this is in preparation in the form of an international standard (ISO/CD 23500, guidance for the preparation and quality management of fluids for haemodialysis and related therapies) [10].

\section{Competing interests}

The author declares that they have no competing interests.

\section{References}

1. Bek MJ, Laule S, Reichert-Junger C, Holtkamp R, Wiesner M, Keyl $\mathrm{C}$ : Methemoglobinemia in critically ill patients during extended hemodialysis and simultaneous disinfection of the hospital water supply. Crit Care 2009, 13:R162.

2. LeChevallier MW, Cawthon CD, Lee RG: Inactivation of biofilm bacteria. Appl Environ Microbiol 1988, 54:2492-2499.

3. Codony F, Morato J, Ribas F, Mas J: Effect of chlorine, biodegradable dissolved organic carbon and suspended bacteria on biofilm development in drinking water systems. J Basic Microbiol 2002, 42:311-319.

4. O'Neill E, Humphreys $\mathrm{H}$ : Surveillance of hospital water and primary prevention of nosocomial legionellosis: what is the evidence? J Hosp Infect 2005, 59:273-279.

5. Pedahzur R, Katzenelson D, Barnea N, Lev O, Shuval HI, Fattal B, Ulitzur S: The efficacy of long-lasting residual drinking water disinfectants based on hydrogen peroxide and silver. Wat Sci Tech 2000, 42:293-298 [http://cat.inist.fr/?aModele=afficheN\& cpsidt=1382183].

6. Ward RA: Worldwide guidelines for the preparation and quality management of dialysis fluid and their implementation. Blood Purif 2009, 27 Suppl 1:2-4.

7. National Patient Safety Agency: Haemodialysis patients: risks associated with water supply (hydrogen peroxide). Central Alert System reference NPSA/2008/RRR007; 30 September 2008 [http://www.nrls.npsa.nhs.uk/resources/?entryid45=59893].

8. Davidovits M, Barak A, Cleper R, Krause I, Gamzo Z, Eisenstein B: Methaemoglobinaemia and haemolysis associated with hydrogen peroxide in a paediatric haemodialysis centre: a warning note. Nephrol Dial Transplant 2003, 18:2354-2358.

9. Ames RG, Stratton JW: Effect of chlorine dioxide water disinfection on hematologic and serum parameters of renal dialysis patients. Arch Environ Health 1987, 42:280-285.

10. International Organization for Standardization: ISO/CD 23500 Fluids for haemodialysis and related therapies [http://www.iso. org/iso/search/iso_catalogue/catalogue_tc/catalogue_detail.htm? csnumber $=45345]$. 